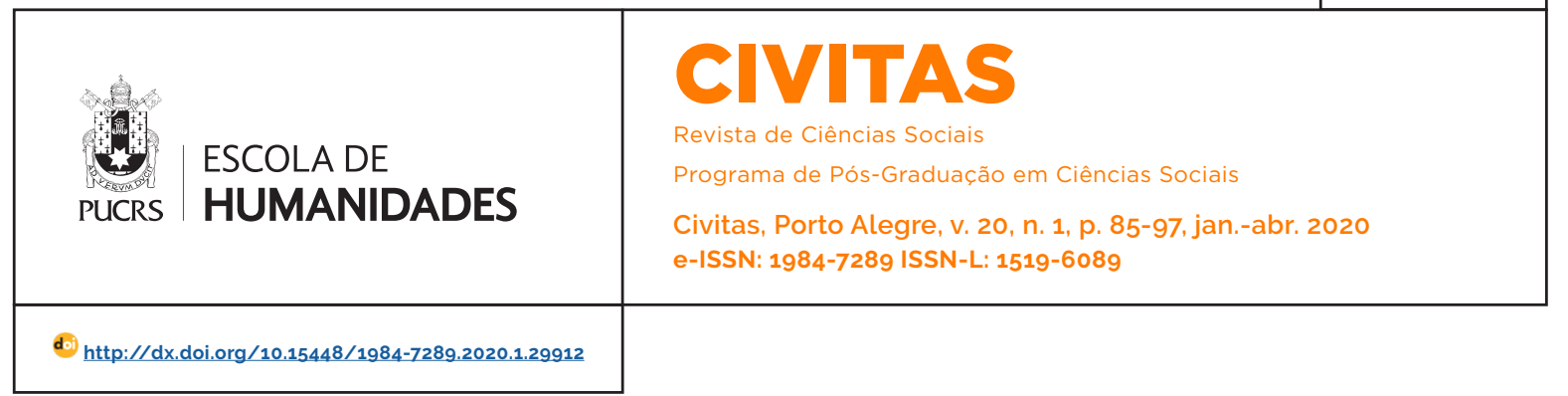

ARTIGOS/ARTICLES

\title{
Atitudes políticas e mundos semânticos: um estudo qualitativo sobre a racionalidade aquém das ideologias políticas
}

\author{
Political attitudes and semantic worlds: a qualitative study of rationality short of \\ political ideologies \\ Actitudes politicas y mundos semánticos: un estudio cualitativo de la racionalidad sin \\ ideologias politicas
}

\section{Emerson Ferreira}

\section{Rocha $^{1}$}

orcid.org/0000-0001-8007-367X

erochedo@gmail.com

Recebido em: 13 fev. 2018 Aprovado em: 5 set. 2019 Publicado em: 25 mai. 2020
Resumo: Este artigo traz um estudo empírico qualitativo sobre as percepções e as atitudes politicas de brasileiros de sete regiões metropolitanas brasileiras. Utilizando dados de 323 entrevistas semiestruturadas, identifica quatro padrões discursivos relacionados a atitudes e a racionalidades políticas distintas. Investiga também a associação desses padrões discursivos com a escolaridade e o grupo ocupacional dos entrevistados. A técnica utilizada para identificar esses padrões é a análise de conteúdo assistida por análise estatística de texto. Os resultados substantivos apontam para as limitações do conceito de ideologia para explicar as atitudes politicas e sugerem agendas de pesquisa para a melhor compreensão sobre como essas atitudes se organizam e sobre o seu papel no funcionamento do sistema político.

Palavras-chave: Atitudes politicas. Ideologia. Classes sociais.

Abstract: This article presents an empirical study on the perceptions and political attitudes of Brazilians from seven different Brazilian metropolitan regions. Using data from 323 semi-structured interviews, the study identifies four discursive patterns related to different political attitudes and rationalities. We also investigate the association of these discursive patterns with the interviewees' schooling and occupation. The technique used to identify these patterns is a content analysis assisted by statistical analysis of text. Substantive results point out to the limitations of the concept of ideology to explain political attitudes. Finally, the study suggests research agendas for a better assessment of how these attitudes are organized and about their role in the functioning of democratic political systems. Keywords: Political attitudes. Ideology. Social classes.

Resumen: Este artículo trae un estudio empírico cualitativo sobre las percepciones y actitudes políticas de brasileños de siete regiones metropolitanas brasileñas. Utilizando datos de 323 entrevistas semiestructuradas, el estudio identifica cuatro patrones discursivos relacionados con actitudes y racionalidades políticas distintas. Se investiga también la asociación de esos patrones discursivos con escolaridad y grupo ocupacional de los entrevistados. La técnica utilizada para identificar estos patrones es el análisis de contenido asistido por el análisis estadístico de texto. Los resultados sustantivos apuntan a las limitaciones del concepto de ideología para explicar las actitudes políticas y sugiere agendas de investigación para la mejor comprensión sobre cómo se organizan estas actitudes y sobre su papel en el funcionamiento del sistema político.

Palabras clave: Actitudes políticas. Ideologia. Clases sociales. 


\section{Introdução}

A questão sobre a racionalidade das atitudes políticas é um tópico candente para as democracias de massas. A formação de atitudes políticas por parte da população em geral é um pré-requisito para que os cidadãos possam sancionar os atores da política institucional (Krosnick e Milburn 1990). Nesse sentido, pesquisadores têm investigado o papel da ideologia como meio de comunicação entre a população em geral e esses atores. A ideia é a de que um espectro ideológico definido, como esquerda/direita, ${ }^{2}$ pode oferecer uma linguagem comum para que atores institucionais e os cidadãos organizem as suas posturas e comportamentos, e mapeiem, em um dado momento, as tendências e as correlações de força no ambiente político. A ideologia seria, assim, um meio para as pessoas organizarem os seus interesses e formulá-los enquanto demandas coletivamente vinculantes.

As pesquisas empíricas nessa literatura têm mostrado que, embora o espectro esquerda/ direita seja relevante nos modernos regimes democráticos, seus significados não são fixos e a maior parte das pessoas não os adota de maneira consistente (Carmines e D'Amico 2015: Ferrer e Velasco 2013; Power e Zucco Jr. 2009; Tarouco e Madeira 2013; Turgeon 2009; Zechmeister e Corral 2013). No Brasil, especificamente, pesquisadores convergem para a conclusão de que há fraca orientação ideológica, sendo as atitudes políticas majoritariamente erráticas ou desestruturadas (Ames e Smith 2010; Carreirão 2002; Oliveira e Turgeon 2015: Rennó e Turgeon 2016). Assim, os estudos orientados pela noção de ideologia tendem a identificar inconsistência nas atitudes políticas dos brasileiros.

O presente estudo questiona se tal inconsistência nas atitudes políticas não seria um artefato dos próprios instrumentos de mensuração adotados nesses estudos. O que esses costumam aferir é se, e em que medida, as pessoas se orientam politicamente por quadros ideológicos predefinidos, geralmente, por referência aos ideários da socialdemocracia de um lado, e do conservadorismo liberal do outro. Questionase aqui se a desestruturação das atitudes nos termos desses quadros ideológicos equivale a uma desestruturação tout à fait. Com dados de entrevistas abertas, e adotando métodos de análise exploratória de dados, investiga-se o modo como as pessoas organizam suas percepções sobre as conjunturas nacionais e locais face às suas aspirações e projetos de vida. Nesse sentido, o estudo vai ao encontro de investigações que procuram identificar atitudes políticas independentemente de um quadro ideológico predefinido teoricamente (Krosnick e Milburn 1990).

A análise exploratória das entrevistas, com suporte em técnicas estatísticas, permitirá também avaliar em que medida padrões de discurso se associam com o nivel de escolaridade e a classe ocupacional dos entrevistados. Como será visto, a literatura chama atenção para essas variáveis quando se trata de investigar atitudes politicas. A classe, porque determina interesses objetivos e condiciona as experiências de vida nas esferas do trabalho e do consumo. A escolaridade, porque afeta a maneira como a linguagem é mobilizada para articular as opiniões e as visões de mundo.

\section{Atitudes políticas e plano discursivo}

Quando se trata de investigar as atitudes politicas enquanto essas se expressam no campo da linguagem, emerge, na literatura, a noção de ideologia (Singer 1999). Um dos grandes desafios dos estudos empíricos é identificar se, e em que medida, o comportamento das pessoas na arena pública é orientado por ideologias políticas, muito especialmente pelo espectro ideológico da esquerda (apoio à intervenção do estado na economia para fins redistributivos e regulatórios e progressismo nas agendas morais) à direita (defesa da minima regulação dos mercados e conservadorismo nas agendas morais) (Ferrer e Velasco 2013). Mas se a definição desse espectro é clara no esteio das doutrinas em economia política, seu significado não é fixo entre diferentes regiões (Zechmeister e Corral 2010) ou entre diferentes

\footnotetext{
2 Toda a literatura que será revista trabalha com a seguinte convenção sobre o que define esse espectro. À esquerda, apoio à intervenção do estado na economia para fins regulatório e redistributivo, assim como progressismo no domínio dos costumes. Á direita, defesa do livre mercado e conservadorismo moral.
} 
individuos em uma mesma região (Zechmeister 2006). Diante disso, pesquisadores da área discutem não apenas a extensão em que as pessoas aderem a ideologias, mas também os próprios mecanismos pelos quais as ideologias operam.

Basicamente, existe de um lado, a acepção da ideologia enquanto um conjunto racionalmente estruturado de crenças. Nesse caso, a orientação ideológica das atitudes e comportamentos políticos só existiria quando as pessoas compreendessem coerentemente o espectro ideológico em termos de suas implicações programáticas, estando aptas a, de maneira analítica e consistente, posicionarem a si mesmas, a outras pessoas e aos atores políticos nesse espectro (Oliveira e Turgeon 2015). De outro lado, compreendem-se as ideologias políticas como "sinalizadoras de orientações" (Singer 1999. 35), quer dizer, como signos sintéticos que permitiriam às pessoas em geral mapearem o cenário político, mesmo sem terem desse uma compreensão clara e circunstanciada.

No Brasil, Singer (1999), alinhado à segunda perspectiva, argumenta que a ideologia cumpre um papel central na definição das atitudes políticas. Já os estudos que se alinham à primeira perspectiva, tendem a mostrar o contrário. Carreirão (2002) revela que a consistência ideológica entre os brasileiros varia de baixa à moderada. O autor considera, ainda, a escolaridade como variável interveniente à relação entre ideologia e atitudes políticas, revelando que, embora entre os mais escolarizados a consistência ideológica seja mais frequente, nem mesmo aí ela é predominante. Por sua vez, em estudo de painel realizado em duas cidades brasileiras de médio porte, Ames e Smith (2010) mostram que a autoclassificação das pessoas como esquerdistas ou direitistas, embora difundida, não é consistente ao longo do tempo. Em outro estudo recente, Oliveira e Turgeon (2015) corroboram esses achados. Os autores revelam que esse tipo de autoclassificação não mantém relação consistente com as opiniões em relação à intervenção do Estado na economia e na prestação de serviços essenciais. Mais ainda, eles investigam como a educação e a sofisticação política ${ }^{3}$ medeiam a relação entre ideologia e atitudes políticas. Seus resultados mostram que, embora as pessoas mais escolarizadas e mais sofisticadas politicamente tendam a se identificar com uma ideologia, seus posicionamentos programáticos continuam sendo inconsistentes com o respectivo quadro ideológico (Oliveira e Turgeon 2015).

O que esses estudos têm em comum é a abordagem das atitudes políticas dentro do ambiente institucional e cognitivo dos sistemas políticos funcionalmente diferenciados. As orientações teóricas e os instrumentos de pesquisa mobilizados visam a mapear as atitudes políticas, da mesma forma que suas expressões e formulações discursivas, enquanto referidas diretamente às disputas por influência e comando sobre os poderes legislativo e executivo, assim como no âmbito da esfera pública. Surge daí a ênfase na ideologia enquanto linguagem especializada para viabilizar a comunicação em ampla escala entre atores políticos e massas, assim como para organizar as tomadas de posição dentro desse ambiente. Sua principal conclusão é a de que, no Brasil, as ideologias não cumprem esse papel de maneira generalizada. Embora destaquem o efeito da escolaridade como moderadora da identificação das pessoas com ideologias, concluem que maiores niveis de educação formal impactam relativamente pouco sobre a consistência ideológica.

Com base em entrevistas em profundidade. este estudo explora como as atitudes políticas se manifestam no posicionamento das pessoas sobre as dificuldades e os empasses para se constituir uma vida boa no Brasil. Parte-se da premissa de que, nas democracias modernas, a persecução dessa meta entrelaça a dimensão dos projetos individuais e coletivos com a construção de acordos societais de coexistência e, portanto, com a mediação e a transformação das relações sociais pela esfera política (Saavedra e Sobottka 2008). Enquanto os estudos sobre ideologia, para

Em principio, o conceito de sofisticação política se refere a um construto tridimensional, envolvendo: interesse por assuntos políticos acesso à informação sobre esses assuntos e habilidade cognitiva para organizar essas informações em nivel abstrato (Luskin 1990). No estudo de Oliveira e Turgeon (2015), o conceito é operacionalizado com base em um indicador sintético: o nivel de conhecimento das pessoas sobre temas políticos especificos. 
investigarem essa trama trabalham com uma série de pressupostos sobre o conteúdo das orientações ideológicas, a metodologia empregada aqui, geralmente designada método Alceste, pressupõe apenas que a ocorrência conjunta das palavras em um enunciado contextualiza o seu uso e. portanto, o seu significado. A partir da análise dessa coocorrência, é possivel identificar "mundos semânticos" ou "percepções globais do mundo" (Reinert 1990), que podem ou não ter a feição de ideologias específicas.

Essa maior independência de pressupostos com relação ao conteúdo das falas tem motivado o emprego do método Alceste em pesquisas sobre temas como identidade nacional (Marchand e Ratinaud 2012). No presente estudo, espera-se que o método permita elucidar como os discursos se articulam ao complexo de aspirações e de medos, de interesses e de aversões que as pessoas manifestam por referência ao modo como instâncias institucionais como estado e mercado afetam as suas vidas. Isso sem definir, a priori, um quadro ideológico específico para essa articulação. Levando em conta ainda o destaque que a literatura sobre atitudes políticas tem dado à escolaridade enquanto variável mediadora, será investigada também a associação entre os padrões discursivos identificados e os niveis de escolaridade das pessoas. Se a escolaridade prediz pouco sobre a consistência ideológica, será que ela explica a familiaridade das pessoas com determinado mundo semântico?

\section{Atitudes políticas e classes sociais}

No âmbito internacional, algumas pesquisas apontam para um declínio relativo no peso da estrutura de classes sobre as atitudes politicas, relacionado às próprias transformações no mundo do trabalho e à relevância emergente de hierarquias não baseadas na posição de mercado para a formação de solidariedades políticas (Clark, Lipset e Rempel 1993). Contudo, essas mesmas pesquisas não negam a relevância da classe enquanto outras apontam para a consistência desse construto na predição de dinâmicas como o comportamento eleitoral (Hout, Brooks e Manza 1995).
No Brasil, a relação entre classe e atitudes políticas ainda não é um tema amplamente abordado. Em geral, os estudos sobre classes se concentram em desenvolver esquemas de classificação adequados às especificidades da sociedade brasileira (Carvalhaes 2015: Santos 2005a; Scalon 1998). Além disso, procuram discernir o poder explicativo desses esquemas sobre fenômenos como mobilidade social (Ferreira 2001; Ribeiro 2006) e discriminação no mercado de trabalho (Santos 2005b). Nesse contexto, destaca-se o trabalho de Scalon (2007). que explora as atitudes de pessoas de diferentes classes sobre a desigualdade. O estudo revela que as classes médias e altas consideram justas desigualdades extremas (maiores que as já observadas) de renda entre ocupações com niveis distintos de status. Por outro lado, em estudo abordando a relação entre estratificação, mobilidade social e atitudes políticas, Rennó e Turgeon (2016) encontram correlações fracas entre classes sociais e atitudes políticas.

Diante disso, esse estudo testa a associação das classes ocupacionais com os padrões discursivos identificados pelo método Alceste. A questão é: quando as atitudes políticas são identificadas de maneira exploratória, e não a partir de um quadro ideológico definido a priori, encontrase uma associação relevante entre essas e as classes sociais das pessoas? Operacionalmente, esse estudo define as classes sociais a partir de grupos ocupacionais desagregados. Embora a estrutura de classes, compreendida como a distribuição de poderes e direitos sobre recursos produtivos relevantes, não se confunda com a estrutura ocupacional (Wright 1980), outros autores têm mostrado que esquemas de classificação mais desagregados costumam permitir uma aproximação empírica mais satisfatória entre classes sociais e atitudes (Grusky e Sørensen 1998).

\section{Metodologia e dados}

Utilizam-se aqui os dados do levantamento Radiografia do Brasil contemporâneo, doravante denominado RBC, realizado pelo Instituto de Pesquisa Econômica (Ipea), entre os anos de 2015 
e 2016. A pesquisa entrevistou 632 pessoas em regiões metropolitanas das cinco macrorregiões brasileiras: Belém - PA, Manaus - AM, Natal - PR, Recife - PE, Salvador - BA, Rio de Janeiro - RJ, São Paulo - SP, Porto Alegre - RS. A seleção dos entrevistados não foi probabilística, de modo que a amostra não pode ser considerada estatisticamente representativa da população dessas regiões. Antes, a pesquisa segue a orientação metodológica da produção de teoria fundamentada em dados (Corbin e Strauss 1990), trabalhando com uma amostra intencional, diversificada em termos de ocupação, renda, escolaridade e região de moradia, com o objetivo de subsidiar o conhecimento indutivo acerca das relações entre posição socioeconômica e atitudes em diferentes esferas como familia, escola, religião e política.

Neste trabalho, serão utilizadas as falas que ocorreram mediante estímulos com os seguintes: "O que você considera ser uma vida boa"?; "Como é ter uma vida boa no Brasil"?; "Quem tem uma vida boa no Brasil"?; "Quais são os problemas do Brasil"?; "E quais os lados positivos"?; e "Como você enxerga a sociedade brasileira hoje em dia"? Trechos de 323 entrevistas foram utilizados para a construção de um corpus, onde consta também a informação sobre a ocupação e a escolaridade dos entrevistados. A descrição da amostra por essas variáveis consta na tabela 1, com as ocupações codificadas segundo o COD-2010, do IBGE.

TABELA 1 - Ocupação e escolaridade.

\begin{tabular}{|c|c|c|c|}
\hline Ocupação & $\begin{array}{l}\text { Código da ocupação } \\
\text { COD-2010 }\end{array}$ & $\begin{array}{l}\text { Frequência } \\
\text { (N) }\end{array}$ & $\begin{array}{l}\text { Proporção } \\
(\%)\end{array}$ \\
\hline Diretores e gerentes & 1 & 27 & $8,4 \%$ \\
\hline Profissionais das ciências e intelectuais & 2 & 139 & $43,0 \%$ \\
\hline Técnicos e profissionais de nível médio & 3 & 20 & $6.2 \%$ \\
\hline Trabalhadores de apoio administrativo & 4 & 19 & $5.9 \%$ \\
\hline $\begin{array}{l}\text { Trabalhadores dos serviços, vendedores dos } \\
\text { comércios e mercados }\end{array}$ & 5 & 56 & $17.3 \%$ \\
\hline $\begin{array}{l}\text { Trabalhadores qualificados, operários e artesãos } \\
\text { da construção, das artes mecânicas e outros } \\
\text { ofícios }\end{array}$ & 7 & 9 & $2,8 \%$ \\
\hline Operadores de instalações e máquinas e montadores & 8 & 6 & $1,9 \%$ \\
\hline Ocupações elementares & 9 & 25 & $7,7 \%$ \\
\hline $\begin{array}{l}\text { Membros das forças armadas, policiais e bom- } \\
\text { beiros militares }\end{array}$ & 0 & 20 & $6,2 \%$ \\
\hline Ocupações mal definidas & & 2 & $0,6 \%$ \\
\hline Total & & 323 & $100,0 \%$ \\
\hline Ensino & & $\begin{array}{l}\text { Frequência } \\
\text { (N) }\end{array}$ & $\begin{array}{c}\text { Proporção } \\
\text { (\%) }\end{array}$ \\
\hline Primário & & 20 & $6.2 \%$ \\
\hline Fundamental & & 34 & $10,5 \%$ \\
\hline Médio & & 85 & $26.3 \%$ \\
\hline Superior & & 148 & $45.8 \%$ \\
\hline Pós-Graduação & & 36 & $11,1 \%$ \\
\hline Total & & 323 & $100,0 \%$ \\
\hline
\end{tabular}

Fonte: Elaboração própria com base em Ipea (2017). 
A metodologia aplicada para explorar esse corpus é a proposta por Reinert (1990), aplicada através do software Iramuteq. A técnica toma como unidade inicial de análise, segmentos de texto que, de maneira geral, equivalem a enunciados. Partindo da representação desses enunciados em uma matriz numérica, uma análise de agrupamento é utilizada para identificar padrões discursivos conforme a coocorrência de palavras. A ideia éa de que, ao não se trabalhar com palavras isoladas, mas sim com sua disposição conjunta em enunciados, os padrões identificados pela técnica retenham informação sobre a intencionalidade latente ao dado textual. O autor propõe, então, que os padrões identificados possam constituir "mundos semânticos" ou "uma mesma percepção global do mundo" (Reinert 1990, 33). Tais padrões são representados graficamente em nuvens, nas quais são dispostos seus termos mais característicos ${ }^{4}$, e devem ser interpretados com auxilio à leitura orientada de partes do corpus submetido à análise. A técnica identifica também a associação dos padrões discursivos com variáveis categóricas, através de testes de associação estatística do tipo
$X^{2}$. Com esse recurso, será investigada a relação dos mundos semânticos com a educação formal e com a ocupação dos entrevistados.

\section{Resultados}

No gráfico 1 apresenta-se o resultado da aplicação do método. Foram identificados quatro padrões discursivos. Note-se que a formação dos agrupamentos tem uma natureza hierárquica. A primeira divisão está representada na horizontal. A cifra de $45,9 \%$, disposta na legenda desse eixo pode ser considerada uma medida do peso relativo dessa primeira divisão binária para o resultado total da análise. Já a cifra de 29,4\%, disposta no eixo vertical, expressa o peso relativo da diferença entre os padrões nos quadrantes superior e inferior esquerdo. Finalmente, a contribuição da subdivisão entre os padrões superior e inferior direito (terceira dimensão omitida no gráfico) é de $24,7 \%$. Substantivamente, o que isso tudo quer dizer é que foram identificados quatro mundos semânticos, sendo que há uma diferença maior entre aqueles representados à esquerda ou à direita do gráfico.

GRÁFICO 1 - Aplicação do método Reinert.

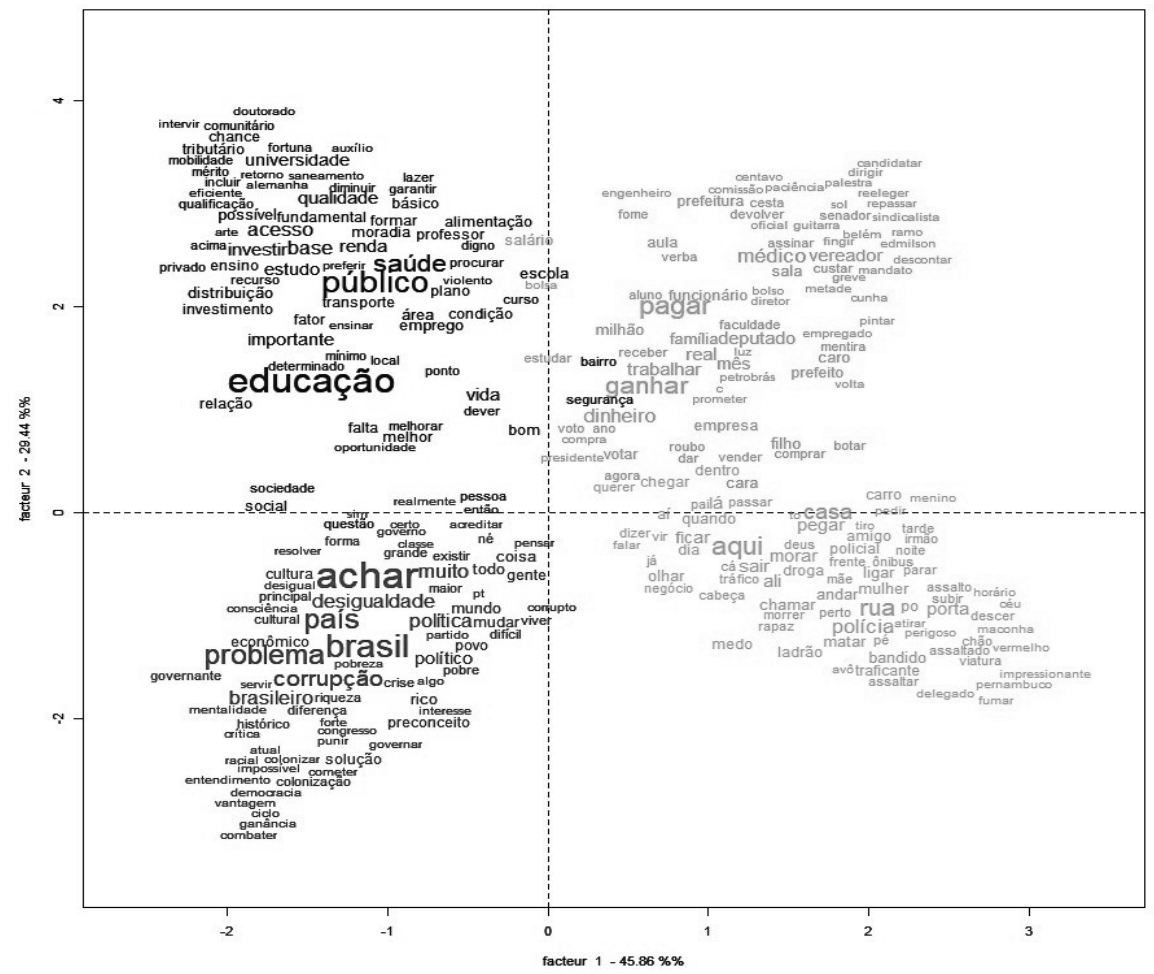

Fonte: Elaboração própria com base em Ipea (2017)

4 O tamanho das palavras no gráfico representa o quanto ela é característica do seu respectivo padrão. 


\section{A semântica do espaço vital}

O padrão representado no quadrante inferior direito se dirige a duas preocupações: segurança e infraestrutura urbana, sendo a primeira a mais premente. O que o caracteriza como um mundo semântico é a relação específica com o espaçotempo. Os lugares e os momentos são referidos como ambiência de uma experiência engajada. Os discursos não localizam esses ambientes de maneira explícita, em um quadro abstrato de coordenadas espaço-temporais. Antes, esses são sempre referidos como ubíquos às vivências. $A$ marcante presença de expressões dêiticas como aqui (termo mais característico do padrão), lá, ali, ai e quando, confirma essa interpretação. Tais expressões modulam as sentenças pois, na medida mesma em que se referem à posição espaço-temporal dos lugares de maneira implícita, os destituem de qualquer coordenada que não seja a própria experiência. Trata-se de uma relação com o mundo enquanto realidade imediata. $O$ discurso dispensa a mediação de construções abstratas e gerais. Não que não haja percepções e ideias gerais em jogo. É que essas são sempre expostas mediante ilustração, pela narração de experiências concretas. Algumas excepcionais, que ilustram por hipérboles. Muitas rotineiras, que ilustram sendo paradigmáticas.

Esse padrão está associado com o nivel primário de ensino (valor $p<0,0001$ ). Isso não quer dizer que apenas indivíduos com essa escolaridade mobilizem essa semântica, mas sim que eles a mobilizam com maior frequência. Quanto às ocupações, ${ }^{5}$ a semântica do espaço vital é mais familiar aos que trabalham em atividades manuais de baixa qualificação, o que se pode compreender pela relação entre baixa remuneração, baixo acesso à infraestrutura e vulnerabilidade à violência urbana. De modo semelhante se pode interpretar a familiaridade daqueles sem ocupação com a semântica do espaço vital. Na amostra, boa parte dessas pessoas encontram alguma fonte de renda em atividades ocasionais pelas vias públicas (levar carros, coletar materiais de maneira esporádica). Essa vida nas ruas encerra também uma relação muito intima com a insegurança.
Destaque-se, ainda, a associação entre a semântica do espaço vital e os profissionais dos serviços de proteção e segurança. Nesse caso, a familiaridade se deve a condições muito específicas da atuação profissional, que estabelece uma relação cotidiana e intensa com questões de segurança pública. Isso vai ao encontro do argumento de que esquemas de classe social muito agregados podem perder de vista caracteristicas especificas de certas profissões, relacionadas a atitudes e comportamentos prováveis (Grusky e Sørensen 1998).

\section{A semântica das funções vitais}

No quadrante superior direito, um padrão discursivo se concentra na expressão de sentimentos de injustiça. No mais das vezes, esses sentimentos se dirigem ao Estado, em criticas a práticas de corrupção, a políticas e a serviços públicos, à alta remuneração de agentes públicos e ao nepotismo. Os sentimentos se dirigem, também, contudo, a instituições de mercado, especialmente, sob a sensação de não reconhecimento dos próprios méritos. Dirigem-se, ainda, a outras pessoas, notadamente a pessoas estereotipadas em uma figura de passividade e de improdutividade. O que caracteriza esse padrão como um mundo semântico não consiste, entretanto, nesse conjunto de temas, que também marca a categoria discursiva analisada na próxima subseção. O que reúne esses enunciados em uma mesma percepção global da realidade é seu apoio no que se pode chamar de funções vitais: a reprodução da vida em familia mediante o trabalho e o ganho do sustento ou do conforto. Em outras palavras, subjaz à produção desses enunciados e ao sentimento de injustiça que eles expressam, um mundo semântico constituído pela relação dos locutores com as funções de produção e de reprodução da vida mediante trabalho e renda.

Note-se o conjunto de termos mais característicos desse mundo semântico: pagar, ganhar, médico, dinheiro, trabalhar, salário, caro, real, mês, filho, família, milhão, deputado, votar, prefeito, prefeitura, empresa, comprar e receber.

\footnotetext{
5 As medidas de associação entre os mundos semânticos e os títulos ocupacionais são expostas no Apêndice.
} 
Trata-se de uma combinação. Há os alvos da crítica, que são as instituições e seus agentes: prefeitura, empresa, deputado e médico. Do outro lado, há os critérios da crítica: familia, trabalho e renda. O sentimento de injustiça está na percepção geral de um mundo distorcido, onde algumas pessoas, instaladas em posições de poder, obtêm vantagens indevidas de modo a comprometer diretamente a realização das funções vitais por parte das pessoas comuns, posição em que os locutores se colocam. Semelhante à semântica do espaço vital, esse padrão expressa uma relação imediata com a realidade. Mesmo as impressões mais gerais são articuladas através de ilustrações particulares. A experiência narrada é a experiência com o mundo em sua concretude.

Há relação com niveis de escolaridade inferiores ao ensino médio (valor $\mathrm{p}=0,011$ ). Assim, embora não tanto quanto a do espaço vital, essa semântica é mais familiar a pessoas com baixa escolaridade. Quanto à ocupação, destaca-se a associação com dirigentes administrativos e comerciais e, também, com trabalhadores dos serviços pessoais. A discrepância entre esses grupos ocupacionais em termos de status socioeconômico chama mais uma vez atenção para certas vantagens em se trabalhar com esquemas de classe pouco agregados. Muito distintos em termos de situação de mercado, esses grupos mantêm, em suas vidas profissionais, uma experiência fortemente marcada pelo controle rigoroso do fluxo de bens de capital, destacadamente dinheiro e trabalho. Os dirigentes administrativos e comerciais, por esse tipo de controle lhes ser incumbência. Os trabalhadores dos serviços pessoais por serem, nessa amostra, majoritariamente trabalhadores autônomos, responsáveis por todo controle do tempo de trabalho e do fluxo monetário em suas atividades.

\section{A semântica da essência nacional}

O padrão discursivo representado no quadrante inferior esquerdo do gráfico 1 compartilha vários temas com a semântica das funções vitais: corrupção, malversação de recursos públicos, o caráter rotineiro de práticas ilícitas ou à margem da moralidade pública, e a falta de confiança em instituições. Contudo, ainda assim o método o identificou como uma percepção global do mundo distinta.
O que diferencia esse padrão como um mundo semântico próprio passa pelo modo como uma concepção essencialista do país estrutura os discursos. Note-se de partida o caráter intelectualista dos enunciados em jogo. Por oposição ao apego à concretude da experiência imediata, que marca os mundos semânticos até agora abordados, aqui a relação com a realidade é mediada por noções abstratas, gerais e, no caso, também totalizantes, como povo e cultura. Destaquem-se os termos: achar, país, problema, corrupção, política, brasileiro, povo, desigualdade e mentalidade. O emprego dos termos cultura e mentalidade (em geral outra designação para "cultura", enquanto espécie de mentalidade coletiva) para qualificar os sujeitos brasileiro e povo [brasileiro] consolidam a tomada de uma essência nacional como conceito metaexplicativo. Da corrupção à desigualdade, as explicações para os problemas do Brasil são, em geral, reconduzidas a essa chave explicativa.

A palavra achar (a mais característica desse mundo semântico) surge geralmente em construções do tipo "Eu acho que [...]". Ao que seguem diferentes teses sobre as mazelas do Brasil. Basicamente, essa construção recorrente posiciona o locutor como um árbitro, cujos juízos a respeito do país, do seu povo e da sua cultura são, em geral, negativos e por vezes fatalistas. Em sintese, o verbo "achar" não delimita uma postura de circunspecção, de dúvida ou de suspensão heurística das próprias certezas. Antes, sua ocorrência opera um movimento retórico que situa o locutor no plano do conhecimento teórico para, assim, autorizá-lo a julgar, com poder de veredito, os porquês de todas as penúrias da população e da ordenação social do país. O que define esse padrão como mundo semântico. quer dizer, o tipo de relação com a realidade ali expressa, parece ser precisamente essa relação não apenas intelectualista, mas de julgamento, aliada à ideia, de pendor fatalista, de uma essência nacional.

A semântica da essência nacional está fortemente relacionada à conclusão do nível superior de ensino (valor $p<0,0001$ ). Quanto às ocupações, há relação com os profissionais 
em direito, em ciências sociais e cultura (valor $\mathrm{p}<0,0001$ ). No caso da presente amostra, esse grupo ocupacional abarca majoritariamente profissionais do direito, inclusive magistrados. Isso é compreensivel, já que o campo jurídico opera exatamente com o tipo de relação com a realidade que marca esse mundo semântico: julgamento e arbitragem mediante recursos intelectuais. Quanto aos cientistas sociais, eles são, por sua vez, sobremaneira afeitos a teses. Há também associação considerável com os profissionais de nivel médio em operações financeiras e administrativas e, também, com os trabalhadores de cálculos numéricos e encarregados do registro de materiais (valor $p=0,001$ ). As atividades não manuais de controle, mesmo que mais técnicas do que intelectuais, conjugadas à vida cotidiana em ambientes de [conversa de] escritório, podem ser o que socializa para uma atitude intelectualista, veemente em suas opiniões.

É importante notar que o adjetivo intelectualista não conota aqui coerência lógica e adequação aos fatos. Não se trata de um padrão discursivo mais racional nesse sentido. O termo intelectualista é empregado apenas para designar o recurso sistemático a noções abstratas e gerais como mediação com a realidade, não fazendo referência à validade ou mesmo à consistência lógica dos argumentos.

\section{A semântica da república}

O padrão representado no quadrante superior esquerdo se dirige a um amplo espectro de temas: serviços como educação, saúde, segurança e transporte; acesso à renda; desigualdade social; falta de investimento em políticas públicas; representatividade política; ineficiências na gestão do estado; corrupção. Termos muito característicos desse padrão são: educação, público, saúde, acesso, renda, qualidade, vida, investir, estudo, universidade, emprego, escola, distribuição, moradia, cidadão e oportunidade. Há forte ênfase sobre educação e saúde como serviços públicos essenciais. A educação, muito destacadamente, é vista como a grande solução para a sindrome de problemas do país, pois seria capaz de formar "cidadãos mais conscientes", chave para uma sociedade civil ativa e virtuosa. A ideia de uma melhor distribuição das oportunidades é muito marcante e vem acompanhada de uma visão moderada sobre o mérito individual. A temática da felicidade aparece explicitamente, mediante o emprego da palavra vida: "vida boa", "vida digna", "qualidade de vida" e "vida melhor".

Esse padrão compartilha com a semântica da essência nacional o pendor intelectualista. Por exemplo: enquanto no mundo das funções vitais se fala em ganhar e pagar, aqui se fala em emprego. Enquanto no mundo das funções vitais se fala do vereador ou do deputado, aqui se fala da coisa pública. Ainda, enquanto no mundo semântico do espaço vital se fala em bandido, assalto e polícia, aqui se emprega o termo segurança pública. Em suma, as questões não são enunciadas à maneira de situações concretas, mas em termos de entidades gerais abstratas. O uso do vocábulo fator é outro índice dessa atitude. Esse aparece em construções como: "um dos fatores". Ao que segue uma exposição do que seria uma ou um conjunto particular de causas para determinado dilema social.

Embora compartilhe com a semântica da essência nacional a atitude intelectualista, há uma diferença de referencial crítico: no lugar da ideia de essência nacional, as críticas aqui se apoiam na ideia de coisa pública e em um ideal difuso de cidadão consciente. Pode-se dizer que, na semântica da essência nacional, a atitude intelectualista deriva suas teses de um culturalismo de fundo, enquanto na semântica da república, de elementos mais ou menos difusos de doutrinas políticas modernas. Na primeira, os juízos morais se dirigem ao "brasileiro" como tipo coletivo estereotipado. Na segunda, esses juízos tomam como base indivíduo-cidadão típico idealizado.

A semântica da república está associada ao nivel de pós-graduação (valor $p<0,0001$ ). É razoável pensar que a prolongada experiência de vida dentro das universidades leve a uma exposição ao repertório republicano. Quanto às ocupações, existe familiaridade com os profissionais de ensino e com os especialistas em organização da administração pública e de empresas (valor $p<0,0001$ ). Em ambos os casos, 
as funções exercidas colocam os profissionais em relação direta com constelações diversificadas de interesses e projetos de vida que buscam solução em ambientes institucionais regulados.

\section{Discussão}

Como já mencionado, a literatura considera que orientações ideológicas bem estruturadas constituiriam uma condição para a comunicação entre a população, em nível individual ou de grupos de interesse, e atores políticos institucionalizados. Isso, por oferecer uma linguagem adequada à organização racional das atitudes, assim como para o mapeamento dos cenários políticos. O que se mostra aqui, todavia, é que diferentes posições no espaço social não estão apenas relacionadas a diferentes interesses, mas também a diferentes padrões de racionalidade e de significação do mundo social. À conclusão de que o cidadão brasileiro em geral não compreende bem as ideologias políticas (Ames e Smith 2010; Carreirão 2002; Oliveira e Turgeon 2015), pode-se contrapor o argumento de que essas ideologias simplesmente não fazem sentido para boa parte dos brasileiros.

O tipo de racionalidade que marca as semânticas vitalistas, por exemplo, explica porque a maior parte da população não opera de maneira consistente com ideologias. Uma relação com a realidade mediada por doutrinas abstratas é algo estranho àqueles mundos semânticos. Não porque as percepções ali sejam erráticas. É que prevalece uma relação muito mais direta com a vivência de questões sensiveis. É por referência a essa vivência que os discursos operam com critérios de vida digna e estabelecem relações de causalidade a respeito do que torna essa vida mais ou menos provável. Isso não contraria o entendimento, por parte da literatura, de que o caráter abstrato e analítico das ideologias as torna estranhas à maior parte da população (Carreirão 2002; Oliveira e Turgeon 2015), mas altera uma conclusão substantiva. Não se trata de uma desestruturação generalizada das atitudes políticas, mas de uma estruturação que ocorre fora das referências doutrinárias e programáticas das ideologias.

É possivel perceber algumas afinidades entre mundos semânticos e orientações ideológicas.
No domínio do intelectualismo, particularmente familiar à minoria de brasileiros com ensino superior ou pós-graduação, a semântica da república parece tornar posicionamentos de esquerda mais pregnantes. A forte ênfase em valores humanistas e a referência ao ideário republicano encerram uma inclinação favorável a políticas sociais. Já à semântica da essência nacional, posições direitistas podem se insinuar face às percepções fatalistas sobre o caráter do povo e sobre a atuação do Estado brasileiro. Contudo, ainda aqui, não é o espectro ideológico esquerda/direita que orienta os enunciados. Articulados a partir de uma disposição escolástica, os discursos recorrem a um repertório eclético de teses, de doutrinas, e de preconceitos "sofisticados" (racionalizações) para oferecerem um diagnóstico geral sobre as problemáticas abordadas. Isso indica também que, pelo menos em parte, a mensuração de maior consistência ideológica entre os mais escolarizados se deve ao fato de essas pessoas, por dominarem os códigos abstratos, estarem mais aptas a racionalizarem suas respostas de modo a aparentarem o tipo e a coerência ideológica que os instrumentos de pesquisa sugerem como desejável. A maior consistência ideológica medida entre as pessoas mais escolarizadas pode, portanto, ser menos função da elaboração sofisticada das suas opiniões politicas e mais de um viés de aceitabilidade social em suas respostas aos questionários (Turgeon 2009).

A principal implicação dos resultados presentados aqui para a literatura nacional é a sugestão de que se dê menor ênfase aos instrumentos tradicionalmente utilizados para identificar ideologias, e de que se passe a mobilizar estratégias mais exploratórias de investigação. Espera-se ter mostrado que essas estratégias podem se alinhar a métodos robustos que permitem, inclusive, o teste formal de hipóteses de associação. O método aplicado aqui permitiu até mesmo certo controle sobre a arbitrariedade intrinseca aos processos de classificação em análise de conteúdo. Sem embargo, esse método tem sido valorizado por oferecer um procedimento padrão, baseado na análise estatística de coocorrências, permitindo uma inspeção integral do corpus que 
minimiza a influência de expectativas especificas do pesquisador sobre o conteúdo dos dados textuais (Marchand e Ratinaud 2012).

Isso não quer dizer que o método dispense a atividade hermenêutica. Muito pelo contrário, a própria interpretação dos padrões identificados pela rotina de análise exige a leitura natural de trechos característicos desses padrões. A questão é a possibilidade de aumentar o grau de intersubjetividade dos procedimentos adotados para a categorização do material analisado.

Do ponto de vista do sistema político, os resultados desse estudo apontam para a necessidade de dar mais atenção aos mecanismos de mediação entre a formação de doutrinas ideológicas, que ocorre em circuitos socialmente especializados de intelectuais, políticos profissionais e burocratas de um lado, e, do outro lado, as percepções e racionalidades das pessoas em geral. Mesmo que na acepção menos restritiva de sinalizadores as ideologias sejam bem operantes (Singer, 1999), explorar de modo mais abrangente os discursos e as sensibilidades políticas abre caminho para se compreender de maneira mais acurada processos de mudança. Os quadros ideológicos que os instrumentos tradicionais operacionalizam têm o seu tempo e lugar históricos de origem. Suas lentes, portanto, nem sempre serão as mais adequadas para identificar novas ou simplesmente outras constelações de atitudes políticas, especialmente, se essas não operarem com os mesmos pressupostos de abstração e conceitualização da realidade.

\section{Referências}

Ames, B. e A. E. Smith. 2010. Knowing left from right: ideological identification in Brazil, 2002-2006. Journal of politics in Latin America 2, n० 3: 3-38. https://doi. org/10.1177/1866802×1000200301.

Carmines, E. G. e N. J. D'Amico. 2015. The new look in political ideology research. Annual Review of Political Science 18, n० 1: 205-216. https://doi.org/10.1146/annurev-polisci-060314-115422.

Carreirão, Y. de S. Identificação ideológica e voto para presidente. 2002. Opinião Pública 8, n 1: 54-79. https:// doi.org/10.1590/s0104-62762002000100004.
Carvalhaes, F. A. de O. 2015. A tipologia ocupacional Erikson-Goldthorpe-Portocarero (Egp): uma avaliação analítica e empírica. Sociedade e Estado 30, n 3: 673-703. https:// doi.org/10.1590/s0102-69922015.00030005.

Clark, T. N., S. M. Lipset, e M. Rempel. 1993. The declining political significance of social class. International Sociology 8, $n^{\circ}$ 3: 293-316. https://doi. org/10.1177/026858093008003003.

Corbin, J. and A. Strauss. 1990. Grounded theory research: procedures, canons and evaluative criteria. Zeitschrift Für Soziologie 19, n 6: 418-427. https://doi. org/10.1515/zfsoz-1990-0602.

Ferreira, M. C. Permeável. 2001. Ma non troppo: a mobilidade social em setores de elites, Brasil-1996. Revista Brasileira de Ciências Sociais 16, n 47: 141-160. https:// doi.org/10.1515/zfsoz-1990-0602

Ferrer, L. E. G. y R. Q. Velasco. 2013. Izquierda y derecha: formas de definirlas, el caso latinoamericano y sus implicaciones. América Latina Hoy 65. 79-105. https:// doi.org/10.1515/zfsoz-1990-0602.

Grusky, D. B. and J. B. Sørensen. 1998. Can class analysis be salvaged? American Journal of Sociology 103, $n^{\circ} 5$ : 1187-1234. https://doi.org/10.1086/231351.

Hout, M., C. Brooks, and J. Manza. 1995. The democratic class struggle in the United States, 1948-1992. American Sociological Review 60, n 6: 805-828. https://doi. org/10.2307/2096428.

Krosnick, J. A. and M. A. Milburn. 1990. Psychological determinants of political opinionation. Social Cognition 8, n 1: 49-72. https://doi.org/10.1521/soco.1990.8.1.49.

Luskin, R. C. 1990. Explaining political sophistication. Political Behavior 12, n 4: 331-361. https://doi.org/10.1007/ bfo0g92793.

Marchand, P. et P. Ratinaud. s. d. L'identité nationale: un "grand débat" loin d'être clos. Acesso em Agosto, 26 2018. http://www.iramuteq.org/Members/pmarchand/ lidentite-nationale-un-grand-debat

Oliveira, C., e M. Turgeon. 2015. Ideologia e comportamento político no eleitorado brasileiro. Opinião Pública 21, n 3 : 574-600. https://doi.org/10.1590/1807-01912015213574.

Power, T. J., e C. Zucco Jr. 2009. Estimating ideology of brazilian legislative parties, 1990-2005: a research communication. Latin American Research Review 44, $\mathrm{n}^{\circ}$ 1: 218-246. https://doi.org/10.1353/lar.0.0072.

Reinert, M. 1990. Alceste: une méthodologie d'analyse des données textuelles et une application: Aurelia de Gerard de Nerval. Bulletin de Méthodologie Sociologique 26, $n^{\circ}$ 1: 24-54. https://doi. org/10.1177/075910639002600103

Rennó, L. e M. Turgeon. 2016. A psicologia política das classes sociais no Brasil: atributos das atitudes politicas por estratificação e mobilidade social. Dados $59, n^{\circ} 1$ : 11-52. https://doi.org/10.1590/00115258201670.

Ribeiro, C. A. C. 2006. Class, race, and social mobility in Brazil. Dados 49, $n^{\circ}$ 4: 833-873

Saavedra, G. A. e E. A. Sobottka. 2008. Introdução à teoria do reconhecimento de Axel Honneth. Civitas 8, n 1: 19-28. https://doi.org/10.15448/1984-7289.2008.1.4319. 
Santos, J. A. F. 2005a. Uma classificação socioeconômica para - Brasil. Revista Brasileira de Ciências Sociais 20, n 58: 2745. https://doi.org/10.1590/s0102-69092005000200002.

Santos, J. A. F. 2005b. Efeitos de classe na desigualdade racial no Brasil. Dados 48, n 1: 21-65. https://doi. org/10.1590/s0011-52582005000100003.

Scalon, C. 2007. Justiça como igualdade? A percepção da elite e do povo brasileiro. Sociologias 9, n 18: 126-149. https://doi.org/10.1590/s1517-45222007000200007.

Scalon, M. C. 1998. Mapeando estratos: critérios para escolha de uma classificação. Dados 41, n 2: 337-375 https://doi.org/10.1590/s0011-52581998000200003.

Singer, A. 1999. Esquerda e direita no eleitorado brasileiro: a identificação ideológica nas disputas presidenciais de 1989 e 1994. São Paulo: Editora Universidade de São Paulo. https://doi.org/10.33594/000000072.

Tarouco, G. da S. e R. M. Madeira. 2013. Partidos, programas e o debate sobre esquerda e direita no Brasil. Revista de Sociologia e Politica 21, n 45: 149-165. https:// doi.org/10.1590/s0104-44782013000100011.

Turgeon, M. 2009. 'Just thinking': attitude development, public opinion, and political representation. Political Behavior 31, n 3: 353-378. https://doi.org/10.1007/ S11109-008-9079-4.

Wright, E. O. 1980. Class and occupation. Theory and Society 9 (1): 177-214.

Zechmeister, E. 2006. What's left and who's right? A Q-Method study of individual and contextual influences on the meaning of ideological labels. Political Behavior 28, n 2: 151-173. https://doi.org/10.1007/s11109-0069006-5.

Zechmeister, E., y M. Corral. 2010. El variado significado de 'izquierda'y 'derecha'en América Latina. Perspectivas desde el barómetro de las Américas 38: 1-10.

Zechmeister, E. J. and M. Corral. 2013. Individual and contextual constraints on ideological labels in Latin America" Comparative Political Studies 46, n 6: 675-701. https://doi.org/10.1177/0010414012463880.

\section{Emerson Ferreira Rocha}

Doutor em Sociologia pela Universidade de Brasilia. Professor Adjunto do departamento de Sociologia da Universidade de Brasilia (UnB), Brasília, DF, Brasil.

\section{Apêndice}

Apresenta as medidas de associação entre mundos semânticos e as classes ocupacionais. Para os testes de associação, foi utilizada a classificação em nivel mais desagregado que aquele apresentado na tabela 1. A razão disso é que, nos testes, se procurou considerar as especificidades de cada ocupação no nivel mais desagregado, enquanto na tabela 1 preserva-se a sintese para fins de uma exposição sumária. O leitor deve notar que se trata de diferentes niveis de agregação da mesma classificação. O nivel de agregação apresentado na tabela 1 corresponde ao primeiro dígito dos códigos de ocupação COD-2010 adotados pelo IBGE. Nos testes apresentados aqui, o código é considerado até o segundo dígito. Por exemplo: ao código 12 nesse apêndice, para "Dirigentes administrativos e comerciais", corresponde o código 1, referente à categoria mais agregada dos "Diretores e gerentes", na tabela 1.

\section{Espaço vital}

\section{Nome da ocupação COD-2010}

Código da ocupação Valor "p" para o

COD-2010 teste de associação

Trabalhadores elementares da mineração, da construção, da indústria de transformação e transporte

96

Trabalhadores dos serviços de proteção e segurança

Operários e oficiais de processamento de alimentos, da madeira, da confecção e afins

Dirigentes administrativos e comerciais

Trabalhadores elementares da mineração, da construção, da indústria de transformação e transporte interior de edifícios

Sem ocupação

Ajudantes de preparação de alimentos

Trabalhadores domésticos e outros trabalhadores de limpeza no
94

91

$<0,0001$

$<0,0001$

$<0,0001$

$-$

$<0,0001$

54

$<0,0001$

75

$=0,001$

12

$=0,008$ 


\section{Nome da ocupação COD-2010}

Código da ocupação

COD-2010
Valor "p" para o

teste de associação

Profissionais de nivel médio da saúde e afins

32

$=0,028$

Condutores de veículos e operadores de equipamentos móveis

pesados

83

$=0,038$

\section{Funções vitais}

Nome da ocupação COD-2010

Código da ocupação COD-2010
Valor "p" para o teste de associação

\begin{tabular}{lcl}
\hline Dirigentes administrativos e comerciais & 12 & $<0,0001$ \\
Trabalhadores dos serviços pessoais & 51 & 13 \\
Dirigentes e gerentes de produção e operação & 32 & $=0,003$ \\
Profissionais de nível médio da saúde e afins & 32 & $=0,003$ \\
Montadores & $82,013=0$
\end{tabular}

\section{Essência nacional}

\begin{tabular}{|c|c|c|}
\hline Nome da ocupação COD-2010 & $\begin{array}{l}\text { Código da } \\
\text { ocupação COD-2010 }\end{array}$ & $\begin{array}{l}\text { Valor "p" para o } \\
\text { teste de associação }\end{array}$ \\
\hline Profissionais em direito, em ciências sociais e cultura & 26 & $<0,0001$ \\
\hline $\begin{array}{l}\text { Profissionais de nivel médio em operações financeiras e } \\
\text { administrativas }\end{array}$ & 33 & $=0,001$ \\
\hline $\begin{array}{l}\text { Trabalhadores de cálculos numéricos e encarregados } \\
\text { do registro de materiais }\end{array}$ & 43 & $=0,001$ \\
\hline Profissionais das ciências e engenharias & 21 & $=0,004$ \\
\hline Profissionais do ensino & 23 & $=0,005$ \\
\hline Profissionais da saúde & 22 & $=0,006$ \\
\hline Trabalhadores de atendimento direto ao público & 42 & $=0,011$ \\
\hline $\begin{array}{l}\text { Técnicos de nível médio da tecnologia da informação e } \\
\text { das comunicações }\end{array}$ & 35 & $=0,017$ \\
\hline Profissionais de nivel médio das ciências e das engenharias & 31 & $=0,037$ \\
\hline Escriturários & 41 & $=0,043$ \\
\hline
\end{tabular}

\section{República}

Nome da ocupação COD-2010
Código da ocupação COD-2010
Valor "p" para o teste de associação

Profissionais do ensino

Especialistas em organização da administração públi-

ca e de empresas

$<0,0001$

Profissionais da tecnologia da informação e comunicações

25

$=0,008$ 